\title{
Kidney cancer in Saudi Arabia
}

\section{A 25-year analysis of epidemiology and risk factors in a tertiary center}

Sultan S. Alkhateeb, ABU, FSUO, Ali S. Alothman, MBBS, Abdulmalik M. Addar, MBBS, Raed A. Alqahtani, MBBS, SBU, Tarek M. Mansi, MBBS, SBU, Emad M. Masuadi, Mphil, PhD.

\section{ABSTRACT}

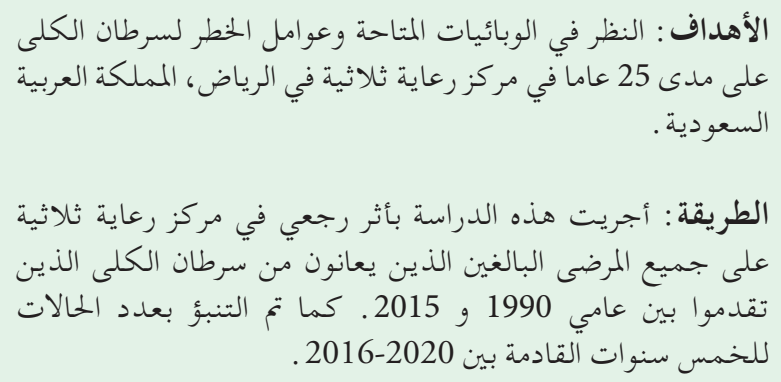

Objectives: To evaluate available epidemiological data and risk factors for kidney cancer in a tertiary care center in Riyadh, Saudi Arabia, over a period of 25 years.

Methods: This retrospective study conducted in a tertiary care center included all adult patients with primary kidney cancer who presented and were managed between 1990 and 2015. Based on this information, we forecast the incidence of the disease in our center over the next 5 years (2016 to 2020).
Results: In total, 371 patients were included in the study. The mean age of the patients was 56.3 years and the majority were male (61\%). Among the patients, $55.8 \%$ were diagnosed incidentally. At the time of diagnosis, $53.2 \%$ were hypertensive, $46.2 \%$ were diabetic, $39.1 \%$ had dyslipidemia, and $25 \%$ were smokers. In addition, most patients were obese $(42.3 \%)$ or overweight $(30 \%)$. The most frequent histopathological variants were clear cell and chromophobe. Most patients presented with Stage 1. Minimally invasive surgery (laparoscopic, robotic) was performed in $55 \%$ of cases. Based on these data, we predicted that 172 new cases will present at our tertiary care center in 5 years from 2016 to 2020.

Conclusion: The incidence in kidney cancer is increasing and is associated with an alarming increase in the prevalence of associated risk factors.

Saudi Med J 2018; Vol. 39 (5): 459-463 doi: 10.15537/smj.2018.5.22641

From the King Saud bin Abdulaziz University for Health Sciences, College of Medicine, Riyadh, Kingdom of Saudi Arabia.

Received 26th January 2018. Accepted 28th March 2018.

Address correspondence and reprint request to: Dr. Abdulmalik M. Addar, King Saud bin Abdulaziz University for Health Sciences, College of Medicine, Riyadh, Kingdom of Saudi Arabia. E-mail: abdulmalikaddar@gmail.com ORCID ID: orcid.org/0000-0001-6969-7158

Disclosure. Authors have no conflict of interests, and the work was not supported or funded by any drug company. 
$\mathrm{K}$ idney cancer is one of the most common malignancies affecting adults, accounting for $4 \%$ of all malignancies. ${ }^{1}$ Hypertension, diabetes mellitus, cigarette smoking, and obesity are risk factors for the disease. Men are more commonly diagnosed than women, at a ratio of $2: 1$. The incidence increases with age and most people are diagnosed between the ages of 55 and 74 years. Survival increases with early diagnosis of localized disease. ${ }^{2}$ Among the histological variants, clear cell is the most common (70\%), followed by papillary $\left(10 \%\right.$ to $15 \%$ ) and chromophobe $(5 \%){ }^{3}$ Kidney cancer is often detected incidentally during routine imaging for other causes rather than presenting symptomatically. Surgical management is the mainstay of curative treatment. With increasing morbidity, nephron sparing and minimally invasive procedures have emerged as treatment options that are associated with lower morbidity and improved mortality. ${ }^{4}$

In Saudi Arabia, detailed and up-to-date epidemiological data are lacking in kidney cancer. The latest cancer registry report in 2013 showed that kidney cancer has an age-standardized rate (ASR) of 2.4/100,000, accounting for $2.3 \%$ of all cancers. The incidence has increased by $33 \%$, with most cases presenting late in the disease course. However, there are currently no national cancer control programs aimed at early detection and prevention. ${ }^{5}$

In this study, we aimed to investigate the epidemiology and risk factors of kidney cancer in a single tertiary center in Riyadh, Saudi Arabia, over a period of 25 years. We analyzed the mode of presentation, associated risk factors, histological variants, disease recurrence and mortality, hoping to obtain a better understanding of the disease.

Methods. After obtaining the necessary approval from the Institutional Review Board, this retrospective study was conducted at King Abdulaziz Medical City (KAMC) in Riyadh, Saudi Arabia. All adult patients (aged >18 years), with primary kidney cancer who presented and were managed between 1990 and 2015 were included. Diagnosis was based on computed tomography (CT) scans and pathology reports. Variables studied included demographics (age, year of presentation, gender), risk factors (hypertension, diabetes, obesity, smoking), mode of presentation (incidental, symptomatic), pathological stage and grade, type of surgical management (open radical nephrectomy, open partial nephrectomy, laparoscopic radical nephrectomy, laparoscopic partial nephrectomy, robotic), and prognosis (mortality, recurrence). Histopathology type and grading were determined on the basis of pathology reports. If pathological staging was not available, clinical stage was used. Recurrence was defined as any recurring tumor that was detected after completion of treatment of the primary tumor. Data were split into 5 cohorts according to the date of presentation: Cohort 1 (January 1, 1990 to December 31, 1994), Cohort 2 (January 1, 1995 to December 31, 1999), Cohort 3 (January 1, 2000 to December 31, 2004), Cohort 4 (January 1, 2005 to December 31, 2010), and Cohort 5 (January 1, 2011 to December 31, 20015).

Data were analyzed using IBM-SPSS software (version 23.0). Categorical variables were represented by frequencies and percentages. Variables were analyzed and compared using chi-squared and t-tests. $\mathrm{P}<0.05$ was considered to indicate statistical significance. Trends in kidney cancer from 1990 to 2015 and forecasting of the incidence over the next 5 years (2016-2020) were analyzed using Minitab version 17.

Results. In total, 371 patients met the inclusion criteria defined as adult patients (aged $>18$ years), with primary kidney cancer who presented and were managed between 1990 and 2015. The demographic data of the included patients are presented in Table 1 . The majority of the patients are male $(61 \%)$ and $31 \%$ were aged $>65$ years. Most patients were either overweight $(30.1 \%)$ or obese $(42.1 \%)$. Hypertension was the most common comorbidity among this patient population followed

Table 1 - Demographics and baseline characteristics of 371 adult patients (aged $>18$ years), with primary kidney cancer who presented and were managed between 1990 and 2015.

\begin{tabular}{lr}
\hline Variable & $\mathbf{n ~ ( \% )}$ \\
\hline Gender & \\
Male & $225(60.9)$ \\
Female & $146(39.1)$ \\
Age at presentation (years) & \\
$<45$ & $69(18.6)$ \\
$45-54$ & $99(26.9)$ \\
$55-64$ & $88(23.7)$ \\
$\geq 65$ & $115(30.8)$ \\
Body mass index & \\
Underweight & $7(1.9)$ \\
Normal & $95(25.6)$ \\
Overweight & $112(30.1)$ \\
Obese & $157(42.3)$ \\
Mode of presentation/risk factors & \\
Incidental & $207(55.8)$ \\
Symptomatic & $164(44.2)$ \\
Hypertension & $197(53.2)$ \\
Smoking & $93(25.0)$ \\
Diabetes mellitus & $171(46.2)$ \\
Dyslipidemia & $145(39.1)$ \\
\hline
\end{tabular}


by diabetes, dyslipidemia and smoking. Incidental presentation was more common than symptomatic presentation $(55.8 \%$ versus $44.2 \%$ ).

Table 2 shows a comparison of the 5 cohorts, each representing a 5 -year duration during the period from 1990 to 2015. There was significant difference between the number of male and female patients in each cohort $(p=0.786)$, although the majority were males in all groups. The incidence of smoking, hypertension and diabetes increased significantly across the 5 cohorts $(p<0.0001, p=0.001$, and $p=0.005)$. Based on the trends in these data, as well as the observed incidence of obesity and dyslipidemia, we predicted that 172 new cases will present at our tertiary care center in the 5 years from 2016 to 2020 (Figure 1).
A significantly greater proportion of patients in cohort 5 were diagnosed at an earlier stage in comparison to those in the other cohorts $(p<0.0001)$. Clear cell carcinoma was the most common pathology type with no significant difference found between the cohorts. Minimally invasive surgery (laparoscopic and robotic) was significantly more common type of surgery in Cohorts 4 and 5 compared to the rates in the earlier groups $(p<0.0001)$. There was a significant decrease in mortality across the cohorts $(p<0.0001)$ and no significant difference in the recurrence rates was observed (Figures $2 \& 3$ ).

Discussion. Our study is the largest local study of the epidemiology of kidney cancer and the associated

Table 2 - Comparison of 5 groups, each representing a 5-year period from 1990-2015.

\begin{tabular}{|c|c|c|c|c|c|c|}
\hline Variable & $\underset{n=25}{\text { Group }} 1$ & $\begin{array}{c}\text { Group } 2 \\
n=32\end{array}$ & $\underset{n=45}{\text { Group }} 3$ & $\begin{array}{c}\text { Group } 4 \\
n=113\end{array}$ & $\begin{array}{c}\text { Group } 5 \\
\mathrm{n}=156\end{array}$ & $P$-value \\
\hline Gender & & & & & & 0.786 \\
\hline Male & $13(52.0)$ & $17(53.1)$ & $27(60)$ & $71(62.8)$ & $95(60.9)$ & \\
\hline Female & $12(48.0)$ & $15(46.9)$ & $18(40)$ & $42(37.2)$ & $61(39.1)$ & \\
\hline Mean age at presentation $( \pm S D)$ & $56.1 \pm 13.8$ & $54.5 \pm 16.4$ & $54.6 \pm 13.8$ & $60.3 \pm 13.7$ & $56.3 \pm 13$ & 0.047 \\
\hline Smoking & $0 \quad(0)$ & $0 \quad(0)$ & $1 \quad(2.2)$ & $5(4.5)$ & $39(25.0)$ & 0.000 \\
\hline Hypertension & $7(28.0)$ & $8(25.0)$ & $14(31.1)$ & $60(53.1)$ & $83(53.2)$ & 0.001 \\
\hline Diabetes mellitus & $7(28.0)$ & $5(15.6)$ & $12(26.7)$ & $41(36.3)$ & $72(46.2)$ & 0.005 \\
\hline Mode of presentation & & & & & & 0.026 \\
\hline Incidental & $8(34.8)$ & $11(35.5)$ & $13(33.3)$ & $46(44.2)$ & $87(55.8)$ & \\
\hline Symptomatic & $15(65.2)$ & $20(64.5)$ & $26(66.7)$ & $58(55.8)$ & $69(44.2)$ & \\
\hline T-stage & & & & & & 0.000 \\
\hline Stage 1 & $5(27.8)$ & $11(40.7)$ & $15(37.5)$ & $37(35.6)$ & $80(51.6)$ & \\
\hline Stage 2 & $5(27.8)$ & $5(18.5)$ & $8(20.0)$ & $14(13.5)$ & $28(18.1)$ & \\
\hline Stage 3 & $2(11.1)$ & $4(14.8)$ & $6(15.0)$ & $22(21.2)$ & $44(28.4)$ & \\
\hline Stage 4 & $6(33.3)$ & $7(25.9)$ & $11(27.5)$ & $31(29.8)$ & $3 \quad(1.9)$ & \\
\hline Histopathology & & & & & & 0.073 \\
\hline Clear cell & $15(75.0)$ & $21(84.0)$ & $33(80.5)$ & $70(70.7)$ & $90(58.1)$ & \\
\hline Papillary & $1 \quad(5.0)$ & $1(4.0)$ & $3(7.3)$ & $10(10.1)$ & $19(12.3)$ & \\
\hline Chromophobe & $0 \quad(0)$ & $2(8.0)$ & $(0)$ & $13(13.1)$ & $29(18.7)$ & \\
\hline Oncocytoma & $2(10.0)$ & $1(4.0)$ & $1 \quad(2.4)$ & $0 \quad(0)$ & $7 \quad(4.5)$ & \\
\hline Urothelial & $1 \quad(5.0)$ & $0 \quad(0)$ & $1 \quad(2.4)$ & $3(3.0)$ & $4 \quad(2.6)$ & \\
\hline Other & $1 \quad(5.0)$ & $0 \quad(0)$ & $3 \quad(7.3)$ & $3(3.0)$ & $6 \quad(3.9)$ & \\
\hline Surgery type & & & & & & 0.000 \\
\hline Open radical & $16(94.1)$ & $24(96.0)$ & $31 \quad(100)$ & $50(62.5)$ & $41(26.3)$ & \\
\hline Open partial & $1 \quad(5.9)$ & $1(4.0)$ & (0) & $8(10.0)$ & $29(18.6)$ & \\
\hline Laparoscopic radical & (0) & $0 \quad(0)$ & (0) & $19(23.8)$ & $66(42.3)$ & \\
\hline Laparoscopic partial & $(0)$ & $(0)$ & (0) & $3(3.8)$ & $17(10.9)$ & \\
\hline Robotic radical & (0) & $(0)$ & (0) & $0 \quad(0)$ & $3 \quad(1.9)$ & \\
\hline Mortality & $5(20.0)$ & $7(23.3)$ & $13(30.2)$ & $27(26.2)$ & $10 \quad(6.4)$ & 0.000 \\
\hline Recurrence & $1 \quad(4.8)$ & $6(24.0)$ & $10(26.3)$ & $15(16.0)$ & $26(16.7)$ & 0.249 \\
\hline
\end{tabular}




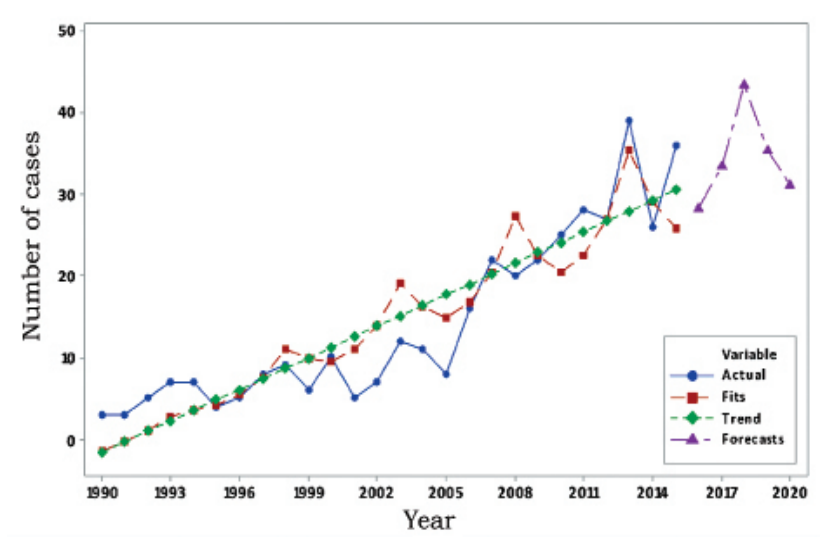

Figure 1 - Time series decomposition plot for frequency. Trend in the incidence of kidney cancer from 1990 to 2015 and a forecast for the period from 2016 to 2020 (fitted trend equation $\mathrm{Yt}=-2.91+1.286 \times \mathrm{t}) . \mathrm{Yt}-$ fitted trend $\mathrm{t}$

risk factors in Saudi Arabia. We observed an increasing trend in the incidence of kidney cancer at our tertiary care center during the 25-year period from 1990 and 2015, which was in accordance with our previously published data. ${ }^{6}$ Similar trends have been observed in studies in North America, Europe, and Asia. ${ }^{7,8}$ This trend may be linked to the increased incidence of hypertension, obesity, and smoking in Saudi Arabia. ${ }^{9,10}$ In addition, the increased use of imaging also correlates with the rise in the incidental detection of renal masses. ${ }^{11,12}$

Our study revealed a rising trend in the incidental diagnosis of renal masses at an earlier stage of the disease. This correlates with most of the recently reported data. In a meta-analysis by Rossi et al, ${ }^{13} 84.4 \%$ of incidental presentations were either Stage 1 or Stage 2. An increase in the use of minimally invasive surgery in the last decade and a decrease in mortality rates are also consistent with most of the published data. A metaanalysis of the use of laparoscopic procedures showed that this type of surgery was associated with a decrease in overall mortality although there was no change in disease recurrence. ${ }^{14}$

Alarmingly, our study shows an increase in the incidence of smoking, hypertension and diabetes mellitus in parallel with the increase in the incidental diagnosis of kidney cancer. Smoking is a wellestablished independent risk factor for kidney cancer that is dose-dependent and associated with an advanced stage at diagnosis. ${ }^{15}$ Also, people with hypertension are twice as likely to have kidney cancer than normotensive individuals. ${ }^{16}$ The role of diabetes as a risk factor for kidney cancer has been a matter of controversy, ${ }^{17}$ although more recent evidence indicates that it is a significant risk factor. ${ }^{18}$ In this study, we noted a

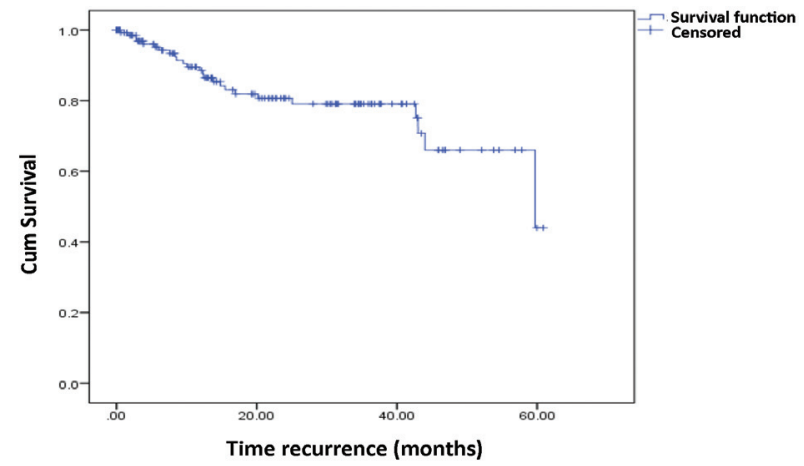

Figure 2 - Kaplan-Meier curve showing time of recurrence. Mean= 47.9 months; median $=59.7$ months

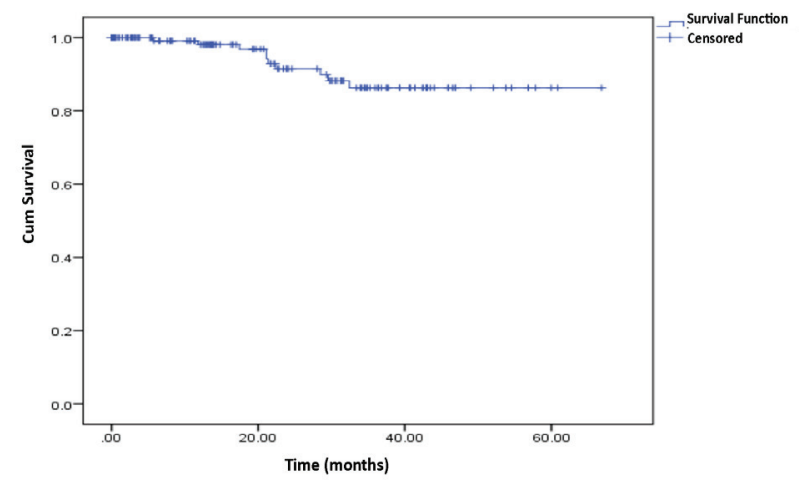

Figure 3 - Kaplan-Meier curve showing time of recurrence. Mean= 47.9 months; median $=59.7$ months

significant increase in the incidence of diabetes among patients with kidney cancer.

The mean age at diagnosis was 57.1 ( \pm standard deviation (SD) 13.8) years across all 5 cohorts. This is in accordance with the information obtained from the Saudi Cancer Registry, which reports a mean age of 56 years for males and 49 years for females. ${ }^{19}$ In addition, clear cell carcinoma remains the most common pathology in all the cohorts followed by papillary in most of the cohorts. These data are consistent with worldwide prevalence. ${ }^{7}$

Obesity has been linked as a risk factor for kidney cancer in a large cohort study conducted in the United States. ${ }^{20}$ In our study, obesity data were available only for Cohort 5, in which $42.3 \%$ of the patients were obese and $30.1 \%$ were overweight. These data indicate that most of the kidney cancer patients had an abnormally high BMI and provides supports for a link between a high BMI and kidney cancer. 
Dyslipidemia, another risk factor that was examined only in Cohort 5, was identified in $39.1 \%$ of patients. The role of dyslipidemia as a risk factor for kidney cancer is unclear and has been suggested by many studies. A study by Zhang et $\mathrm{al}^{21}$ in China showed that high low-density lipoprotein (LDL) levels were frequent among kidney cancer patients and most common in those with clear cell kidney cancer.

The mean time for recurrence was 47.9 months and the median was 59.7 months. The mean for mortality was 60.8 months. Furthermore, the number of cases diagnosed in Cohort 5 was 6 times greater than that in Cohort 1 , illustrating an alarming rise in the incidence of kidney cancer in Saudi Arabia. These results need to be confirmed in population-based studies that should lead to better planning and implementation of awareness and prevention programs designed to minimize the effects of modifiable risk factors associated with kidney cancer. In Europe, a decrease in the incidence of kidney cancer in the 1990s was linked to the decrease in smoking prevalence. ${ }^{22}$ A community-based study in Saudi Arabia showed that the prevalence of smoking in some regions in Saudi Arabia was as high as $91.9 \%$ and having fun was one of the motives for smoking. ${ }^{23}$ This emphasizes the lack of knowledge about the harm associated with tobacco smoking.

Study limitations. First, this study is subject to the inherent limitations of a retrospective study design. Second, the study was conducted in a single tertiary care center in Saudi Arabia, which could represent a referral bias. Third, the influence of genetics on kidney cancer was not addressed.

In conclusion, our study shows an increasing trend in the prevalence of kidney cancer in a subset of the Saudi population; this is associated with an alarming increase in the prevalence of hypertension, smoking and diabetes mellitus. Population-based studies are required to confirm our findings, and resources should be directed toward improving awareness, prevention and early detection of kidney cancer.

\section{References}

1. PDQ Cancer Genetics Editorial Board. Genetics of Kidney Cancer (Renal Cell Cancer) (PDQ $\left.{ }^{\circ}\right)$ : Health Professional Version [Internet]. PDQ Cancer Information Summaries. Bethesda (MD): National Cancer Institute (US); 2002.

2. Kabaria R, Klaassen Z, Terris MK. Renal cell carcinoma: Links and risks. Int J Nephrol Renovasc Dis 2016; 9: 45-52.

3. Chow WH, Dong LM, Devesa SS. Epidemiology and risk factors for kidney cancer. Nat Rev Urol 2010; 7: 245-257.
4. Capitanio U, Montorsi F. Renal cancer. Lancet 2016; 387: 894-906.

5. Abomelha MS. Trends of genitourinary cancer among Saudis. Arab J Urol 2011; 9: 199-202.

6. Alkhateeb SS, Alkhateeb JM, Alrashidi EA. Increasing trends in kidney cancer over the last 2 decades in Saudi Arabia. Saudi Med J 2015; 36: 698-703.

7. Znaor A, Lortet-Tieulent J, Laversanne M, Jemal A, Bray F. International variations and trends in renal cell carcinoma incidence and mortality. Eur Urol 2015; 67: 519-530.

8. Arabsalmani M, Mohammadian-Hafshejani A, Ghoncheh M, Hadadian F, Towhidi F, Vafaee K, et al. Incidence and mortality of kidney cancers, and human development index in Asia; a matter of concern. J Nephropathol 2016; 6: 30-42.

9. Memish ZA, Jaber S, Mokdad AH, AlMazroa MA, Murray CJL, Al Rabeeah AA. Burden of disease, injuries, and risk factors in the Kingdom of Saudi Arabia, 1990-2010. Prev Chronic Dis 2014; 11: 140176.

10. Almutairi KM. Trends in current tobacco use, smoking rates and quit attempts among Saudi population during periods of 17 years (1996-2012): Narrative review article. Iran J Public Health 2015; 44: 170-175.

11. Patard JJ. Incidental renal tumours. Curr Opin Urol. 2009; 19: 454-458.

12. Gill IS, Aron M, Gervais DA, Jewett MAS. Clinical practice. Small renal mass. N Engl J Med 2010; 362: 624-634.

13. Rossi SH, Hsu R, Blick C, Goh V, Nathan P, Nicol D, et al. Meta-analysis of the prevalence of renal cancer detected by abdominal ultrasonography. Br J Surg 2017; 104: 648-659.

14. Liu G, Ma Y, Wang S, Han X, Gao D. Laparoscopic versus open radical nephrectomy for renal cell carcinoma: A systematic review and meta-analysis. Transl Oncol 2017; 10: 501-510.

15. Ridge CA, Pua BB, Madoff DC. Epidemiology and staging of renal cell carcinoma. Semin Intervent Radiol 2014; 31: 3-8.

16. Colt JS, Schwartz K, Graubard BI, Davis F, Ruterbusch J, DiGaetano R, et al. Hypertension and risk of renal cell carcinoma among white and black Americans. Epidemiology 2011; 22: 797-804.

17. Chow WH, Devesa SS. Contemporary Epidemiology of Renal Cell Cancer. Cancer J 2008; 14: 288-301.

18. Tseng CH. Type 2 Diabetes Mellitus and Kidney Cancer Risk: A Retrospective Cohort Analysis of the National Health Insurance. PLoS One 2015; 10: e0142480.

19. Saudi Health Cancer. Cancer Incidence Report Saudi Arabia 2013. [cited 2016]. Available from URL: http:// www.chs.gov.sa/Ar/HealthCenters/NCC/CancerRegistry/ CancerRegistryReports/2013.pdf

20. Adams KF, Leitzmann MF, Albanes D, Kipnis V, Moore SC, Schatzkin A, et al. Body size and renal cell cancer incidence in a large US cohort study. Am J Epidemiol 2008; 168: 268-277.

21. Zhang G, Zhu Y, Luo L, Zhang H, Gu C, Sun L, et al. Prevalence of dyslipidaemia in patients with renal cell carcinoma: a casecontrol study in China. BJU Int 2014; 113: E75-E81.

22. Bosetti C, Bertuccio P, Chatenoud L, Negri E, La Vecchia C, Levi F. Trends in mortality from urologic cancers in Europe, 1970-2008. Eur Urol 2011; 60: 1-15.

23. Abdel Rahim BEE, Mahfouz MS, Yagoub U, Solan YMH, Alsanosy RM. Practice and attitude of cigarette smoking: A community-based study. PLoS One 2014; 9: (4). 